\title{
Editorial
}

\section{Pharming plant genetic resources}

Nearly all cultures, from ancient times to today, have used plants for medicine, exploiting their secondary metabolites as pharmaceutical agents. Over $90 \%$ of the developing world's population relies heavily on herbal medicines to meet many of their healthcare needs, while in Europe and North America the popularity of herbal medicines is increasing at a steady annual rate of at least 15\%. Currently, the value of the global trade in medicinal plants is of the order of US\$60 billion per year, and its potential market size by 2050 has been projected by the World Health Organization (WHO) to be as high as US\$5000 billion. According to the WHO's estimate, over 30\% of the world's plant species — totalling more than 80,000-have at one time or another been used for medicinal purposes. It is believed that perhaps as many as 6000 species of plants are extensively used in traditional, folk, herbal and modern medicines as a source of conventional pharmaceuticals, either directly in the form of raw material, indirectly as a source of extracted active ingredients or as a chemical lead for the synthesis of valuable biomolecules. Although nearly 1500 species are actively traded, and over 600 are in widespread commercial use in the USA as herbal (medicinal) products, only a few species are purposefully farmed on any scale. In China and India, the major consumers and producers of herbal medicines, some 150-250 species are systematically cultivated. As a result, $80 \%$ of the 700,000 tons of medicinal plant material thought to be used annually is obtained from plants grown in the wild.

The phenomenal development of modern medicine during the 20th century resulted in the identification and synthesis of a large number of pharmaceutically active plant constituents. This has led in turn to a declining trend in the use of medicinal plants and crude drugs, especially in mature economies. However, in spite of the fact that synthetic drugs and antibiotics have brought about such a revolution in controlling a range of human diseases, plants retain a critical role as the source of raw material for some of the most important drugs in modern medicine. Atropine, reserpine, quinine and morphine were all discovered through the scientific study of traditional remedies. More recently, the scientifically proven efficacy of herbal medicines has generated a revival of interest in traditional preparations, even in the developed countries. Plant-based drugs are well accepted by millions of consumers in countries as diverse as Germany, Russia, India, China and Japan, and have encouraged the development of integrated systems of medicine. Lately, the US government has established the National Center for Complementary and Alternative Medicine (NCCAM) at the National Institutes of Health at Bethesda, MD, to support basic and applied research in traditional systems of medicine such as Chinese, Ayurvedic etc. with a view to assessing their possible integration for effective treatment with modern medicines.

Although the undirected pharmacological investigation of plant extracts provides opportunities for phytopharmaceutical prospecting for novel molecules, welldocumented therapeutical knowledge is recorded in traditional medical treatises of Ayurveda (India), Shen Nu Materia Medica (China) and the Tibetan medical book Sibu Yidian that could facilitate directed investigation. Similarly, ethnobotanical and traditional medicinal usage in many other cultures offers a rational paradigm for natural drug development based on reverse pharmacology. Both in India (the traditional knowledge digital library, currently being developed by CSIR, New Delhi) and China (the traditional digital library health database) an effort is being made to provide exhaustive descriptions of traditional cultural medicinal usage, and these resources can be expected to both greatly facilitate the identification of molecules with potential pharmaceutical properties via reverse pharmacology, and simultaneously serve as a tool for the protection of the sovereign rights of states and practising communities vis-à-vis stakeholders of these new technologies. Several success stories can be cited concerning the scientific validation of bioactive molecules present in various Ayurvedic plants, including Adhatoda zeylanica as a bronchodilator, Picrorrbiza kurrova for treatment of viral hepatitis, Phyllanthus amarus, Swertia chirayita and Andographis paniculata as hepatoprotectors, Mucuna pruriens to treat Parkinson's disease, Curcuma longa for pre-cancerous conditions, Saraca asoka for dysfunctional uterine bleeding, Commiphora whightii for hyperlipidaemia, Tinospora cordifolia as an immuno-stimulant, Withania somnifera as an immunomodulator and anti-ageing restorer, Hippophae rhamnoides for skin cell regeneration/anti-ageing, Bacopa monnieri as a memory enhancer and piperine from Piper longa to enhance bioavailability. Intensive efforts in this direction should result in a much faster march of drug discovery and develop- 
ment. There are at least 121 major plant drugs ( 45 from tropical plants and 76 from non-tropical species) of known structure, but none is currently produced through synthetic means for commercial use. Notable amongst these are: anti-cancer vinblastine and vincristine from Catharanthus roseus, taxol from Taxus brevifolia, podophyllotoxin from Podophyllum hexandrum, the tranquillizers rescinnamine and reserpine from Rauvolfia serpentina, the anti-malarials quinine from Cinchona species and artemisinin from Artemisia annua, the antiglaucoma pilocarpine from Pilocarpus jaborandi, topical anaesthetic cocaine from Erythroxyllum coca, painkiller morphine and anti-cough codeine from Papaver somniferum, hepatoprotective sylmarine from Silybum marianum, the spasmolytic and cold medicine atropine from Atropa belladonna and Hyoscyamus niger, and cardiac glycosides for the treatment of congestive heart failure from Digitalis species, all of which have been developed thanks to a traditional knowledge base.

With the discovery of more than 120,000 phytochemicals from plants, chemists now have newer opportunities for semi-synthesis, product derivatization, transformation of intermediates into bioactives, newer synthagens etc. Obtaining taxotere (which is more effective than taxol) by semi-synthesis from the 10-DAB (10-De Acetyl BaccatinIII) present in Taxus needles is one of the most notable examples in this regard on two counts: first the use of dispensable/renewable plant parts (needles) instead of the whole plant, thereby conserving the bioresource, and second in its provision of an alternative potential route to meet the requirements of an anti-cancer drug. At the same time, rapid developments in our understanding of the fundamentals of plant secondary metabolism are paving the way for metabolic engineering to recruit phytochemical biogenesis partially or completely in newer organisms, cell types or biosystems including microbes, bioreactors etc. While the specifically medicinal plants are attracting increasing research interest, some commonly consumed plants (particularly legumes like soybean) are emerging as medicinal in their own right, on the strength of their richness in certain isoflavones that are, in pure drug form, potential candidates for hormone replacement therapy in post-menopausal women.

It is, therefore, an appropriate time to pay systematic attention to the pharming of the genetic resources of medicinal plants to meet the demand for their valuable ingredients, and to encourage product development, standardization and validation. We need to focus on the pharmacological validation of herbal remedies, quality control and to establish minimum standards of certification based on analytical testing. Since such a high proportion of raw material is obtained from the wild, it is becoming a priority to develop agro-technologies for the large-scale cultivation and processing of medicinal plants to ensure their sustainable utilization.

With this special issue of Plant Genetic Resources: Characterization and Utilization, we have sought to focus on various areas of interest from the perspective of plant genetic resources. The coverage here could only be representative: the species described range from lichens through mushrooms to higher plants, while among the topics covered are the cultivation, processing, characterization and in vitro propagation from a conservation and industrial viewpoint of some major species; and finally more general issues such as benefit sharing, value addition, genetic improvement and the utilization of alien resources have been discussed.

I am extremely grateful to all the contributors for their cOoperation, and to Robert Koebner, Editor-in-Chief of $P G R$ : $C E U$ for giving me an opportunity to edit this special issue. My special thanks go also to Ms Mary McPhee, Secretary of the journal for her sustained organizational support.

\section{Umesh C. Lavania}

Central Institute of Medicinal \& Aromatic Plants Lucknow-226015

India

Email: lavania@cimap.res.in

\section{Major source references}

Akerele O, Heywood V and Synge H (eds) (1991) The Conservation of Medicinal Plants. Cambridge: Cambridge University Press.

Dev S (1997) Ethnotherapeutics and modern drug development: potential of Ayurveda. Current Science 73: 909-928.

Evans WC (1996) Trease and Evans' Pharmacognosy, 14th edn. London: W. B. Saunders Co.

Lavania S and Lavania UC (1995) Sustainable progress in the realization of high value medicinal principles of plant origin. Journal of the Indian Botanical Society 74A: 227-232 (Platinum Jubilee Volume).

Lavania UC and Lavania S (1994) Plants for medicine. In: Johri BM (ed.) Botany in India: History and Progress. New Delhi: Oxford \& IBH Publishing Co.

Patwardhan B, Vaidya ADB and Chorghade M (2004) Ayurveda and natural products drug discovery. Current Science 86: 789-799.

Saxena PK (ed.) (2001) Development of Plant-based Medicines: Conservation, Efficacy and Safety. Dordrecht: Kluwer Academic Publishers.

Sharma R (2003) Medicinal Plants of India-An Encyclopaedia. Delhi: Daya Publishing House. 